\title{
Synthesis of Nano-sized Nickel Particles by a Bottom-up Approach in the Presence of an Anionic Surfactant and a Nonionic Polymer
}

\author{
M. S. Hussain ${ }^{1}$ and K. M. A. Haque ${ }^{2 *}$ \\ ${ }^{1}$ National Nanotechnology Center, King Abdul Aziz City for Science and Technology, P.O.B. \\ 6086, Riyadh 11442, Saudi Arabia \\ ${ }^{2}$ Atomic Energy Research Institute, King Abdul Aziz City for Science and Technology, P.O.B. \\ 3892, Riyadh 11483, Saudi Arabia
}

Received 6 September 2009, accepted in final revised form 22 April 2010

\begin{abstract}
Nano-sized nickel particles have been synthesized by a bottom-up approach, using hydrazine as the reducing agent in the presence of an anionic surfactant - sodium-dodecyl sulphate (SDS). The effect of adding a nonionic polymer -polyvinylpyrrolidone (PVP) with an anionic surfactant has been studied at two different temperatures; the rate of reduction increased as the reaction temperature was increased from 60 to $100^{\circ} \mathrm{C}$. These nanoaggregated nickel particles were characterized by using SEM with EDX facilities and TEM. TEM characterization showed the presence of spherical Ni particles as fine as $10 \mathrm{~nm}$ in diameter. However, the SEM images showed a very spiky morphology, very small spherical shaped objects were clearly observed within these spiky structures. The combination of SDS/PVP reaction produced nano-sized nickel particles which were much finer than the reactions where SDS was used on its own. PVP has shown some dispersion power, and was found to be capable of preventing nickel particles from gradual agglomeration.
\end{abstract}

Keywords: Bottom-up; SDS; PVP; $10 \mathrm{~nm}$.

(C) 2010 JSR Publications. ISSN: 2070-0237 (Print); 2070-0245 (Online). All rights reserved.

DOI: $10.3329 /$ jsr.v2i2.3261

J. Sci. Res. 2 (2), 313-321 (2010)

\section{Introduction}

There is a continuous exploitation and exploration of nano-materials which have unusual properties that differ from either the bulk or single atom. Consequently nanometals find applications in diverse fields, such as homogeneous and heterogeneous catalysis [1-4], fuel cell catalysis [6-9], electronics [6] optics [7], magnetism [8], material sciences $[10,11]$ and even in medical and biological sciences [12]. The size of

*Corresponding author: kazi_md_anam@yahoo.com 
the alloy powders currently used in the synthesis of thermal barrier coatings (TBC) by thermal plasma spraying is much bigger than 100um in diameter[14]. The object of this research work was to synthesize nano-sized nickel particles/aggregates. The ultimate aim is to synthesize nano-sized NiCrAlY alloy powders (less than $100 \mathrm{~nm}$ in diameter) for high temperature applications in aerospace and power generation industries in bulk quantities $[13,15]$. It is anticipated that the finer nano-sized particles would reduce the high temperature corrosion.

Whilst the design of nano-materials endowed with size dependant functions is gaining much importance, the synthetic strategies have matched their application needs, making a "made to order" relationship possible. These newer tunable synthetic methodologies offer not only an option of preparing any desired bi- and multi-metallic compositions, but it is also possible to control the size and the inner structure of the resulting nano-metals.

Nano-structured materials can be produced by two different approaches, namely, "top down" and "bottom up" approach. The top down approach is the process of breaking down the bulk metals and subsequent stabilization of the resulting nano-sized metal particles of colloidal protecting agents [13-17]. The bottom up approach on the other hand is the wet chemical nano-particle preparation, which relies on building nanoparticles from the atom level of the metal. The interaction between polymers and surfactants in aqueous solutions has been very popular due to applications of mixed polymer-surfactant systems in various materials systems, such as detergents, hair care products, foams, emulsions, mineral oil recovery, and in gene-therapy DNA-lipid complexes [18]. We report here a synthetic method of preparing nano-structured $\mathrm{Ni}$ particles by bottom up approach, i.e. a wet chemical nano-particle preparation.

Nano nickel particles synthesis has been studied extensively over the past decade due to their unique properties and applications in various fields. In recent years research involving nanoparticles and nanoscale materials has generated a great deal of interest from engineers and scientists of nearly all disciplines. Nano-sized nickel particles have found many applications including catalysts, batteries and in superalloys [19]. Finer the size of the catalysts, higher is the catalytic activity. For example, using $30 \mathrm{~nm}$ nickel particles as catalyst to synthesize optical active3-hydroxybutyric acid methyl ester, the yield rate has been found to be as high as to $85 \%$ and the reaction speed was also found to be 15 times more compared with that of normal nickel catalyst [19]. They can also be used for the preparation of porous metallic ensembles and as fillers for polymer, the electric and magnetic properties of nano nickel particles are strongly dependent on the morphology and shape of the particles [20,21]. Therefore nickel nanoparticles with different morphology and shape, such as nanospheres, hollow sphere, nanorod, nanobelt and core-shell structure, have been synthesized by various methods [22-24]. In fact, nanometer-sized crystallites are often the primary product in precipitation from solution. Such dispersions are inherently unstable and the so-formed nanoscale crystallites become aggregated to form larger particles. $\mathrm{Ni}$ and co-workers have reported a chainlike nickel wire formed by self-assembly of small nickel crystallites in a soft template [25]. 
Many different techniques have been used in the preparation of nano-sized particles, for example, the reduction of metal oxide salts $[19,26]$, decomposition of carbonyls [19] and reduction in solutions by strong reducing agents [27]. Reducing agents used include potassium borohydrides, sodium hypophosphite and hydrazine, which corresponds to the formation of metal borides [27]; metal phosphides and pure metals. In the recent past the use of surfactant- macromolecule clusters as template to prepare inorganic crystals has become an area of much research interest [28,29]. It is now wellknown that water-soluble nonionic macromolecule, such as polyvinylpirrolidone (PVP) or polyethyleneoxide (PEO) interact strongly with anionic surfactant, such as sodium dodecyl sulphate (SDS), in aqueous solution [31,32]. Above the critical association concentration (cac), surfactant aggregate on macromolecule chains in micellar structure, which is known as bound-micelle [32].

\section{Experimental}

\subsection{Materials}

Materials used in this research work were nickel chloride (LOBA Chemie, India electroplating grade) sodium dodecyl sulphate (SDS, Merck specialities private limited 92\%); polyvinylpyrrolidone (PVP Winlab, UK, MW-44000); hydrazine hydrate solution (LOBA Chemie, India, 80\%); Sodium Carbonate (Sigma, 99\%); de-ionized distilled water was used in the preparation of all the solutions. A thermostatically controlled hot plate with magnetic stirrer (Yellow Line) was used in this research work.

\subsection{Synthesis}

The nano-sized nickel particles were synthesized by dissolving $10 \mathrm{~g}$ of $\mathrm{NiCl}_{2}$ in a glass beaker containing $100 \mathrm{~mL}$ of de-ionized water which was maintained at $40^{\circ} \mathrm{C} .50 \mathrm{ml}$ $20 \mathrm{~g} / \mathrm{l}$ of SDS solution ( $1 \mathrm{~g}$ SDS dissolved in $50 \mathrm{ml} \mathrm{H}_{2} \mathrm{O}$ ) and $50 \mathrm{ml} 20 \mathrm{~g} / \mathrm{l}$ of PVP solution ( $1 \mathrm{~g}$ PVP dissolved in $50 \mathrm{ml} \mathrm{H}_{2} \mathrm{O}$ ) were added to the solution. In order to study the effect of PVP on the formation of nano-Ni particles a nickel solution was made by adding $20 \mathrm{~g} / \mathrm{l}$ of SDS only without any PVP. The $\mathrm{pH}$ of the nickel solution was then increased to 10.2 by adding saturated sodium carbonate solution. $150 \mathrm{~mL}$ of hydrazine was added to the solution slowly whilst stirring was on all the time. Temperature of the Ni solution was increased to $60^{\circ} \mathrm{C}$ before adding the hydrazine to the Ni solution. Reaction was also carried out at higher temperatures such as 60 and $100^{\circ} \mathrm{C}$ under reflux conditions. At $60^{\circ} \mathrm{C}$ as the reaction continues appearance of gray/black precipitates in the beaker meant that nickel particles have started to form. This reaction is not instantaneous and can take several hours for the nickel reduction to reach completion. However, under reflux condition at $100^{\circ} \mathrm{C}$ the conversion was very quick (less than 20 minutes), froth formation was minimized. 
Whilst the nickel particles are formed at $60^{\circ} \mathrm{C}$ there is a huge volume expansion of the reacting solution and hence care had to be taken not to spill the solution over the reaction vessel e.g. much bigger beakers were use that could handle the volume expansion of the reacting chemicals. As the reaction proceeded the top of the beaker became covered with thick froth; simultaneously Ni particles were deposited at the bottom of the reaction vessel.

Under reflux condition, however, this volume expansion was very little. The gray/black particles so formed were the aggregated nano-sized nickel particles. The products were collected, centrifuged (4000 rpm), washed with distilled water and ethanol for three times, and finally desiccated at room temperature before characterization. The froth also contained a fair amount of fine Ni particles hence these particles were recovered by washing with acetone and water before drying. It has been observed that hydrazine used from a freshly opened bottle gives much faster reaction.

\subsection{Characterization}

The nickel particles were characterized using, Scanning Electron Microscope (SEM) FEI-NOVA 200Nanolab with EDAX and Transmission Electron Microscope (TEM) JEOL - JEM 2100F.

\section{Results and Discussion}

Hydrazine is a normal reducer its reductive ability varies according to the $\mathrm{pH}$ value of the solution. In acid medium, $\varphi_{\mathrm{N} 2 \mathrm{H} 4}^{\mathrm{o}}$ is $0.23 \mathrm{~V}$ and $\mathrm{N}_{2} \mathrm{H}_{4}$ is easily oxidized to $\mathrm{NH}_{3}$. In a basic medium, $\varphi^{\circ}{ }_{\mathrm{N} 2 \mathrm{H} 4}$ is $-1.16 \mathrm{~V}$ and it can be easily oxidized to $\mathrm{N}_{2}$. At $25^{0} \mathrm{C}, \varphi^{\circ} /{ }_{\mathrm{Ni}}{ }^{2+} / \mathrm{Ni}$ is $-0.221 \mathrm{~V}$, so it is possible to reduce nickel ions in basic medium. The reaction equation between nickel chloride and sodium carbonate in aqueous medium can be written as follows:

Hydrazine is added to the solution containing nickel carbonate at $\left(60^{\circ} \mathrm{C}\right)$ to enhance the reaction rate. The reaction equation between nickel and hydrazine is:

$$
2 \mathrm{Ni}^{2+}+\mathrm{N}_{2} \mathrm{H}_{4}+4 \mathrm{OH}^{-}=2 \mathrm{Ni}+\mathrm{N}_{2} \uparrow+4 \mathrm{H}_{2} \mathrm{O}
$$

Figs. 1 and 2 show images of nickel powders synthesized by using SDS/PVP at $60^{\circ} \mathrm{C}$. Fig. 1 is a TEM image of nickel powders synthesized by using SDS/PVP at $60^{\circ} \mathrm{C}$. Fig 2 is a SEM image of the same nickel powder at magnification of 65,000 . TEM image shows (Fig.1) presence of spherical particles which are less than $30 \mathrm{~nm}$ in diameter. The SEM image (Fig. 2) shows a very spiky morphology of the Ni powders, very small spherical shaped objects can clearly be observed within these spiky structures. 


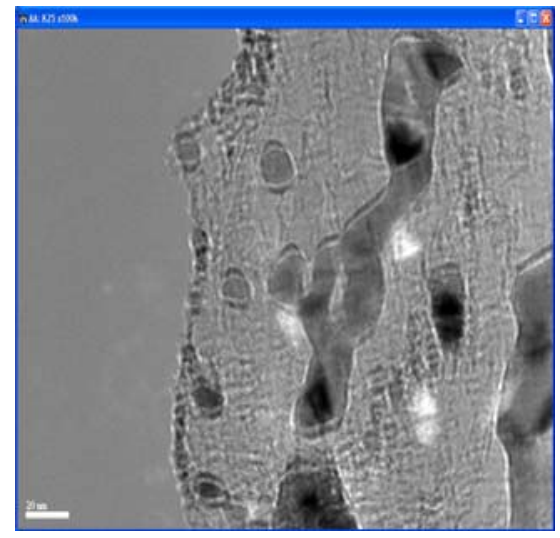

Fig. 1. TEM image of $\mathrm{Ni}$ particles synthesized using SDS/PVP at $60^{\circ} \mathrm{C}$.

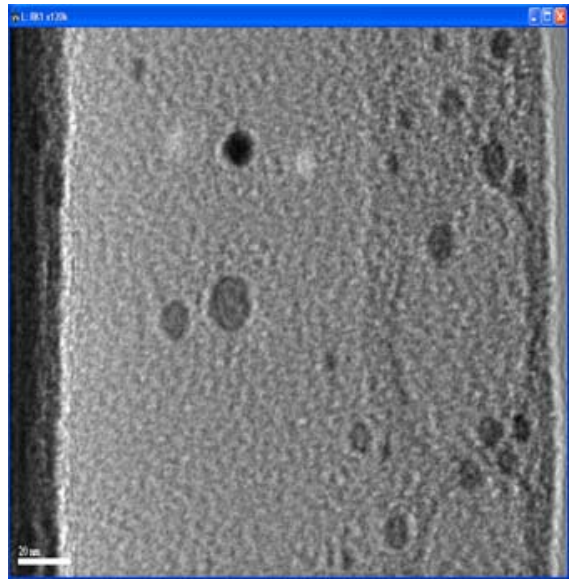

Fig. 3. TEM image of $\mathrm{Ni}$ particles synthesized using SDS/ PVP at $100^{\circ} \mathrm{C}$.

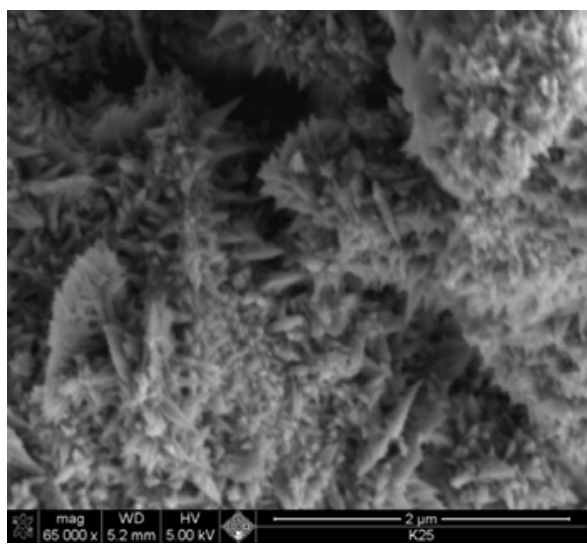

Fig. 2. SEM image of Ni particles synthesized using SDS/PVP at $60^{\circ} \mathrm{C}$. Magnification $\mathrm{x}$ 65,000 .

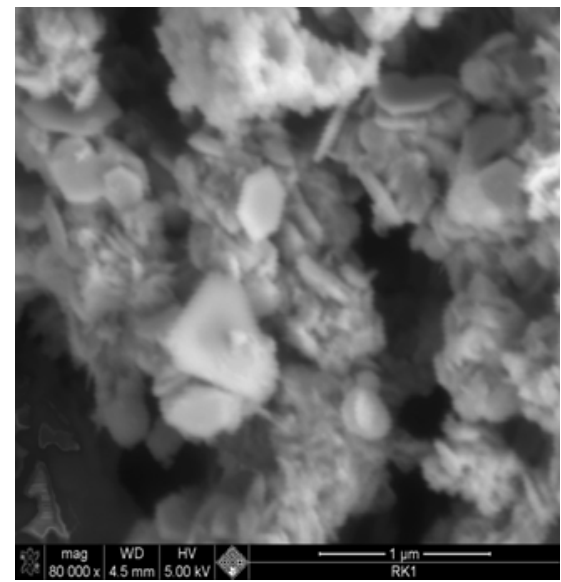

Fig. 4. SEM image of $\mathrm{Ni}$ particles synthesized using SDS/ PVP at $100^{\circ} \mathrm{C}$. Magnification x 80, 000 .

Figs. 3 and 4 are images of Ni powders synthesized under reflux conditions at $100^{\circ} \mathrm{C}$. Fig. 3 is a TEM image of Ni powders synthesized under reflux conditions at $100^{\circ} \mathrm{C}$. Fig. 4 shows SEM image of the same Ni powder sample at a magnification of 80,000. The TEM image (Fig. 3) shows presence many small and spherical particles with diameters less than the diameter of the particles observed in Fig. 1. Measured diameters of these particles are less than 10nm. Fig. 4 is an SEM image at a much higher magnification than that observed in Fig. 2. The image shows objects which are slightly similar to the morphology observed in Fig. 2. The structure is still spiky with 


\section{Synthesis of Nano-sized}

fine spherical structures still present but the effect is much reduced due to higher magnification.

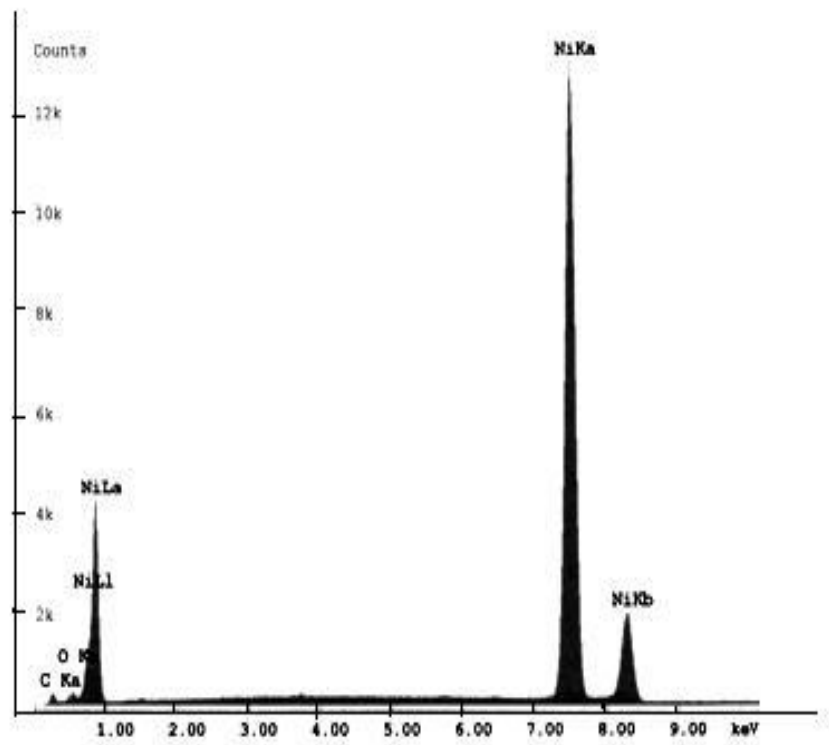

Fig. 5. SEM/EDAX patterns of nano-nickel powder samples prepared with SDS/PVP at $60^{\circ} \mathrm{C}$.

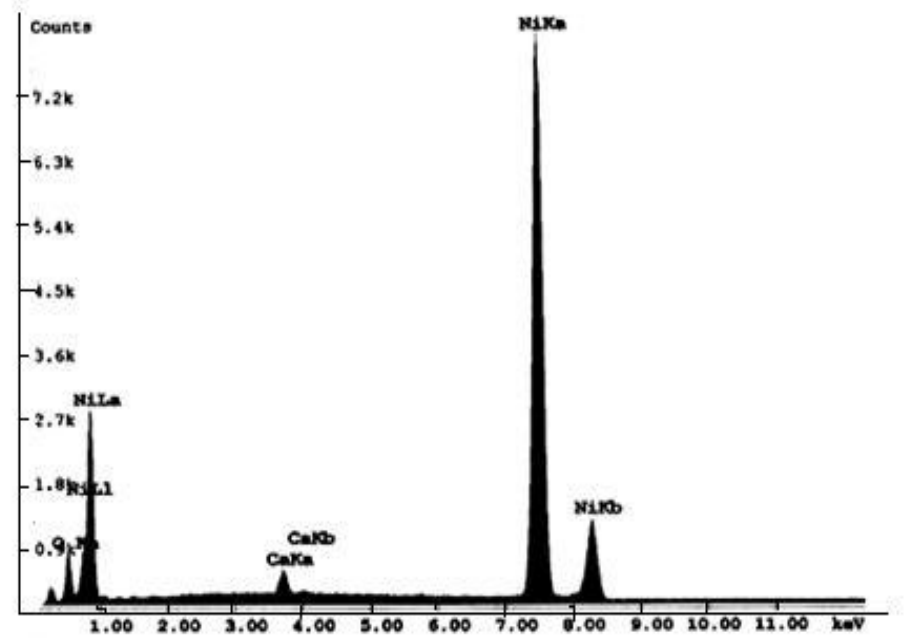

Fig. 6. SEM/EDAX patterns of a nano-nickel sample powder which was prepared with SDS/PVP at $100^{\circ} \mathrm{C}$. 
Figs. 5 and 6 are SEM/EDAX plots of the Ni powders synthesized at 60 and $100^{\circ} \mathrm{C}$ respectively. Both figures show four clear peaks of Ni i.e NiLa, NiL1, NiKa and NIKb. The oxygen and carbon peaks are negligible in Fig. 5, however, the oxygen level observed in Fig. 6 shows some prominence. The peak intensity of the Ni sample synthesized under reflux conditions is much reduced than the sample synthesized at $60^{\circ} \mathrm{C}$. It seems the reduced intensities of the SEM/EDAX plots is an indication the particle size are much finer. The presence of a small Ca peak cannot be accounted for from this experimental work. Clearly the effect of increasing the temperature from 60 to $100^{\circ} \mathrm{C}$ has resulted in the refinement of the nickel particles. Fig. 3. shows the presence of nickel particles which are as fine as $10 \mathrm{~nm}$ in diameter.

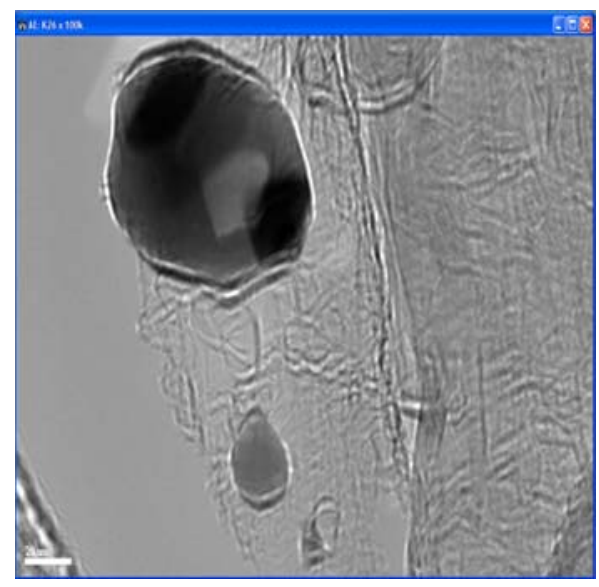

Fig. 7. TEM image of $\mathrm{Ni}$ particles synthesized using SDSonly without PVPat $60^{\circ} \mathrm{C}$. Magnification x 100,000.

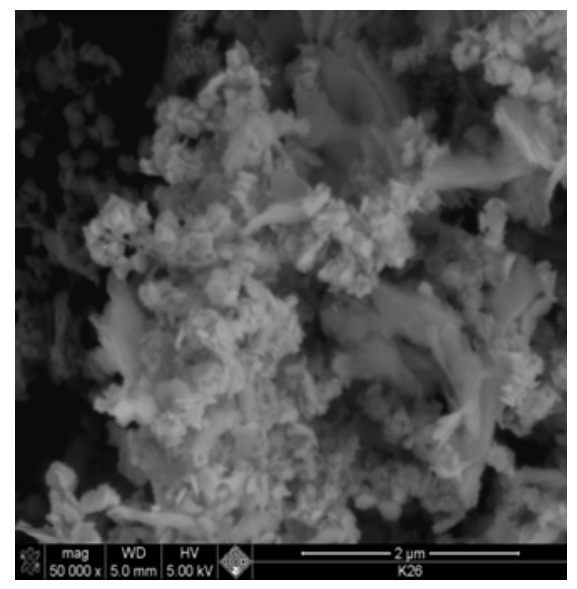

Fig. 8. SEM image of Ni particles synthesized using SDS only without PVP at $60^{\circ} \mathrm{C}$. Magnification x 50,000.

Figs. 7 and 8 are images of nickel particles which were prepared with SDS only i.e. without PVP.TEM image (Fig. 7) shows the particle size is much bigger than Niparticles produced by SDS/PVP at 100 or even $60^{\circ} \mathrm{C}$. The SEM image (Fig.8) does not show the spiky structures as has been observed in the previous images, presence of very small particles are evident.

Nickel crystals are magnentic at the same time nano-sized particles are known to have very large surface areas, hence these synthesized nano-particles will also have very high surface energy. Consequently these fine nickel crystals will be attracted towards each other and very quickly form aggregated nickel particles in order to reduce their surface energies. Our results clearly show that it is possible to synthesize nano-sized Niparticles by using SDS alone which has some template effect. However, PVP has a definite template effect on the formation and retention of the nano-sized Ni particles; 
spherical/spiky nickel nanoparticles are formed due to template effects of PVP and SDS. As the reaction temperature is increased even finer particles are produced with an increase in the rate of particle formation.

Nano-sized nickel particles/aggregates were synthesized. TEM/SEM images show the presence of Ni particles which were as fine as $10 \mathrm{~nm}$ in diameter. The currently used NiCrAlY alloy powder size is much bigger than 100um in diameter [15-17]. The ultimate aim is to synthesize nano-sized NiCrAlY alloy powders (less than $100 \mathrm{~nm}$ in diameter) for high temperature applications in aerospace and power generation industries in bulk quantities.

\section{Conclusions}

Nano-sized nickel particles have been prepared by a simple polymer-surfactant interaction of a nonionic polymer polyvinylpyrrolidone (PVP) with an anionic surfactant, sodium-dodecyl-sulphate SDS in a strong basic medium. Our research shows that the rate of reduction increases as the temperature is increased from $60^{\circ} \mathrm{C}$ to $100^{\circ} \mathrm{C}$ under reflux conditions; under these conditions the particles sizes formed are also much smaller. SEM/EDAX plots indicate when peak heights are reduced this seems like an indication of the presence of even finer particles. The combination of SDS/PVP reaction produced nano-sized nickel particles which were much finer than the reactions where SDS was used on its own. PVP has shown some dispersion power and it has been found to be capable of preventing nickel particles from gradual agglomeration.

\section{Acknowledgment}

We thankfully acknowledge the financial support provided by IRU (Internal Research Unit) at KACST for carrying out this research project. We would also like to thank Abdul Rahman Al Ghihab National Nanotechnology Center at KACST for his cooperation and assistance with SEM work.

\section{References}

1. U. Kreibig, H. Bonnemann, and J.Hormes, Handbook of Surfaces and interfaces of Materials, (Academic Press, San Diego, 2001).

2. H. Bonnemann, R. Richards and R. Synth. Met. Organomet. Inorg. Chem. 54, 209 (2002).

3. M. A. El-Sayed, Acc. Chem. Res. 34, 257 (2001). doi:10.1021/ar960016n

4. J. M. Thomas, B. F. G. Johnson, R. Raja, G. Sankar, and P. A. Midgley, Acc. Chem. Res. 36, 20 (2003). doi:10.1021/ar990017q

5. M. Kralik and A.Biffis, J. Mol. Catal. A: Chem. 177, 113 (2001). doi:10.1016/S1381-1169(01)00313-2

6. C. Cui and C. M. Lieber, Science 291, 851(2001). doi:10.1126/science.291.5505.851

7. A. Eychmuller, J. Phys. Chem B, 104, 6514 (2001). doi:10.1021/jp9943676

8. V. F. Puntes, K. M. Krishnan, and A. P. Alivistos, Science 291, 2115 (2001). doi:10.1126/science. 1057553

9. S. Sun, C. B. Murray, D. Weller, L. Folks, and A. Moser, Science 287, 1989 (2000). 
doi:10.1126/science. 287.5460 .1989

10. C. N. R. Rao, G. U. Kulkarni, and P. Thomas, J. Chem. Soc. Rev. 29, 27 (2000). doi:10.1039/a904518j

11. S. Chen, Adv. Mater. 12, 186 (2000). doi:10.1002/(SICI)1521-4095(200002)12:3<186::AID-ADMA186>3.0.CO;2-E

12. C. M. Niemeyer, Angew. Chem. Int. Ed. Engl. 40, 4128 (2001). doi:10.1002/1521-3773(20011119)40:22<4128::AID-ANIE4128>3.0.CO;2-S

13. M. S. Hussain, Nanodeposition Research Project, KACST, Riyadh, Saudi Arabia, Project No. 26-05 (Final Technical Report, September 2007).

14. M. S. Hussain, Functional and Structural Nanomaterials: Fabrication, Properties, and Applications, TMS, California, USA, 15 to 19 February, 2009 (to be published).

15. M. S. Hussain, Salah Al- Swailem and Ahmed Hala, International J of Nanoparticles 2 (16), 282 (2009).

16. M. S. Hussain, Salah Al-Swailem and Ahmed Hala, ICON 008 CNT, King Saud University, Jeddah, Saudi Arabia (15-19 June 2008).

17. M. S. Hussain and K. M. A. Haque, J. Bangladesh Chemical Society 21 (1), 1 (2008).

18. G. Nizri, S. Magdassi, J. Schmidt, Y. Cohen, and Y. Talmon, Langmuir 20, 4380 (2004). doi:10.1021/la0364441

19. T. S. Harada and A. O. Tai, Chem. Lett. 10, 1131 (1977). doi:10.1246/cl.1977.1131

20. N. Cordente, M. Respaud, F. Senocq, J. M.Casanove, C. Amiens, and B. Chaudret, Nano Lett. 1, 565 (2001). doi:10.1021/n10100522

21. K. H. Kim, Y. B. Lee, E. Y. Choy, H. Park, and C. S. S. Park, Mater Chem. Phys. 86, 420 (2004). doi:10.1016/j.matchemphys.2004.04.011

22. X. M. Ni, Q. B. Zhao, G. D. Zhang, D. D. Yang, and G. H. Zheng, J. Cryst. Growth 280, 217 (2005). doi:10.1016/j.jcrysgro.2005.03.053

23. D. Li and S. Komarneni, J. Am. Ceram. Soc. 89, 1510 (2006). doi:10.1111/j.1551-2916.2006.00925.x

24. J. Bao, Y. Liang, Z. Xu, and L. Si, Adv. Mater. 15, 1832 (2003). doi:10.1002/adma.200305315

25. X. M. Ni, Y. F. Zbang, M. J. Song, and H. G. Zheng, J. Cryst. Growth 299, 365 (2007). doi:10.1016/j.jcrysgro.2006.11.208

26. K. Kimijima and T. J. Sugimoto, Colloid Interface Sci. 286, 520 (2005). doi:10.1016/j.jcis.2005.01.058

27. C. Petit, P. Lixon, and P. M. Pileni, J. Phys. Chem. 97, 12974 (1993). doi:10.1021/j100151a054

28. K. Zhang, C. H. Chew, and C. Q. Xu , Langmuir 15, 3056 (1999). doi:10.1021/la9811158

29. J. R. Scott, Oliver, and O. A Geoffrey, J. Mater. Chem. 8, 1081 (1998). doi: $10.1039 / \mathrm{a} 708598 \mathrm{~b}$

30. X. W. Zheng, Y. Xie, Y. Zhu, X. C. Jiang, and A. H. Yan, Ultrason. Sonochem. 9, 311 (2002). doi:10.1016/S1350-4177(02)00086-X

31. O. Maria, L. Epameinondas, and L.K. Tasoula, Langmuir 20, 5605 (2004). doi:10.1021/la036372d

32. R. Zana, P. Linaos, and J. Lange, J. Phys. Chem. 89, 41 (1985). doi:10.1021/j100247a012 